I Neurol. Neurosurg. Psychiat., 1955, 18, 305.

\title{
LOCALIZED ENLARGEMENT OF THE SPINAL CANAL IN THE ABSENCE OF TUMOUR : A CONGENITAL ABNORMALITY
}

\author{
BY \\ ANTONY JEFFERSON * \\ From the Department of Neurological Surgery, Radcliffe Infirmary, Oxford
}

When Elsberg and Dyke (1934), having studied a series of antero-posterior radiographs of normal spines, reported the range of normal variation in the distance separating the inner borders of the vertebral pedicles, they provided information which has required no important modification since that time. They pointed out that an unusual and localized increase in the distance between the pedicles was to be seen in the presence of intraspinal tumours that were both intrathecal and extrathecal. They wrote (p. 392) that after excluding recent or old fractures of the spine " the enlargement of the vertebral canal described in this paper was found exclusively in expanding lesions within the vertebral canal, and the increase in size always corresponded to the position of the neoplasm ". They observed that only further experience would show whether " enlargement of the interpedicular space" occurred except with an expanding lesion. Elsberg, Dyke, and Brewer (1934) made it clear that an " expanding lesion" was not necessarily a neoplasm, by describing four adolescent patients who had upper thoracic extradural cysts and showed eroded vertebral pedicles. Earl Walker (1944) recorded the findings in four cases where the neurological signs and a study of the pedicles indicated intraspinal neoplasm, but in all four patients a congenital anomaly of the cord was present. In only one case was there any clinical suggestion of spinal cord compression and in two of his cases (p. 581) "there was much more room in the subarachnoid space than usual ". The present writer has been unable to trace published reports recording dilatation of the vertebral canal, apparently similar to that described by Earl Walker, but unassociated with abnormalities of the spinal cord. This publication reports two such cases and, by contrast, a third case in which a somewhat similar vertebral appearance was associated with an extradural cyst, without signs of cord compression.

\footnotetext{
* Nuffield Foundation Fellow.
}

\section{Case Reports}

Case 1.-A woman, aged 22 (R.I. 180511/53), at the age of 11 years was said to have outgrown her strength and developed a slight scoliosis. Remedial exercises were performed with satisfactory results. Five years before admission she began training in a dancing college and discovered that after a day of mental and physical exercise she would find herself very tired. Quite frequently she would wake in the morning with a stiff back. Fifteen months before admission, at a time when she was unusually busy, she began to get an occasional " red hot feeling" on each side of the lower thoracic spine. Because of this complaint she came under medical observation and, subsequently, radiographs of her back were taken. At no time did she have any neurological symptoms, and examination at the time of her admission disclosed no neurological abnormalities. The movements of the spine were full and painless, straight leg raising was unimpaired, and the power, tone, reflexes, and sensation in the legs were entirely normal. The only abnormality on clinical examination was that the spine of the eleventh thoracic vertebra was less prominent than were its neighbours. The radiographs of the spine in the lateral view confirmed that the spine of the eleventh thoracic vertebra (T.11) was rudimentary and also showed stunting of the spine of the twelfth thoracic vertebra. The lateral view showed that the anteroposterior diameter of the spinal canal was increased opposite the bodies of T.12 and the first lumbar vertebra (L.1), suggesting an enlargement of the spinal canal as by an expanding lesion. The antero-posterior view showed a fusion defect in the lamina of T.11 and an unusually slight shadow for the spine of T.12. There was, in addition, widening of the vertebral canal with narrowing of the pedicles of T.12 and L.1 (Fig. 1). With the exception of T.12 and L.1 the measurements between the pedicles throughout this patient's spine approached the lower limit of normal as given by Elsberg and Dyke (1934). The interpedicular distance at T.12 and L.1 increased sharply to the upper limits of normal. (The measurements of the interpedicular distance were : $\mathrm{T} .10=18 \mathrm{~mm}$., T.11 $=20 \mathrm{~mm}$., T.12= $25 \mathrm{~mm}$., L. $1=27 \mathrm{~mm}$., L. $2=25 \mathrm{~mm}$., L. $3=$ $24 \mathrm{~mm}$., L. $4=25 \mathrm{~mm}$.) The figures published by Elsberg and Dyke (1934) are reproduced in the Table. 


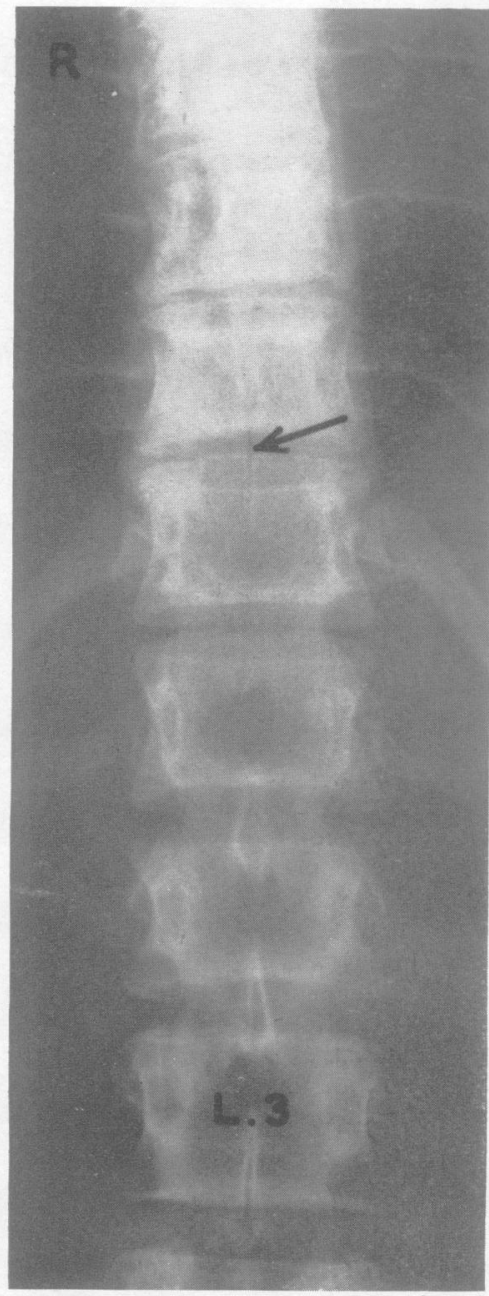

Fig. 1a

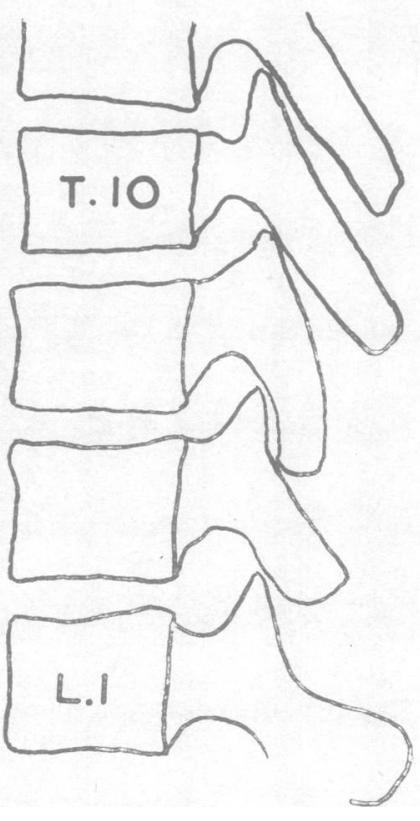

\section{T. 10}

FIG. 2

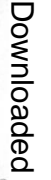

FIG. 1.-Case 1: radiographs of the thorac lumbar junction.

a. Antero-posterior view showing incomple fusion of the spine of T.11 (arrow), al poorly defined spine of T.12, and thinn pedicles T.12 and L.1.

b. Lateral view, in which is seen the ante posterior enlargement of the spinal can opposite the body of L.1 compared, శ example, with L.4.

c. Tracing of the lateral view to show defe tive vertebral spine of T.11 and T.12.

FIG. 2.-Case 2: Radiographs of the thorac을 lumbar junction in the antero-posterior view $\supsetneq$ show abnormality of the pedicles. The appearan 0 is compatible with erosion by an expanding lesio 
TABLE

INTERPEDICULAR DISTANCES AS PUBLISHED BY ELSBERG AND DYKE (1934)

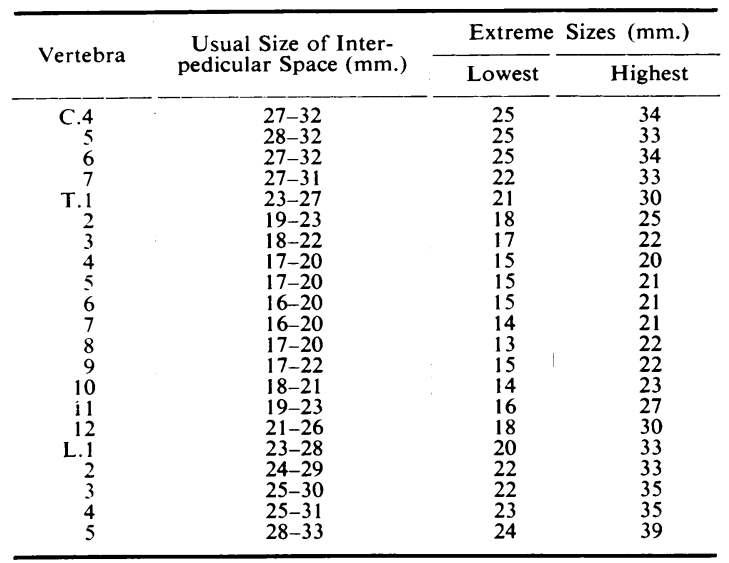

By " usual size" Elsberg and Dyke meant "the range in from 80 to $95^{\circ}$ o of the cases ".

The " extremes" were the lowest and highest figures obtained in the measurements of 200 normal spines.

(Their paper showed that the measurements observed were scarcely affected when the tube-film distance varied between $30 \mathrm{in}$. and 41 in.)

These findings made a lumbar puncture desirable. The initial pressure was $130 \mathrm{~mm}$. of water, there was a slightly sluggish rise on jugular compression, but a normal fall. The fluid contained $40 \mathrm{mg}$. protein $/ 100 \mathrm{ml}$., no red blood cells, and four lymphocytes per c.mm.

The conclusion was drawn from these findings that the spinal canal was enlarged and that in view of the evidence of malformation of the vertebral spines an intraspinal dermoid or lipoma might be present. However, the fact that there were no neurological abnormalities and no manometric block on spinal puncture indicated that compression of the cord had not occurred. Largely at the insistence of the patient and her family, the abnormal region was explored. At operation the spines of T.11 and T.12 were found to be rudimentary, though the supraspinous ligaments and the muscle attachments were well developed. The laminae were removed and the normal amount of extrathecal fat was encountered in the vertebral canal. The unopened dura had a bluish tinge, as though a big cyst might be within, but after the dura was incised it could be seen that the vertebral canal was greatly distended and the spinal cord and its roots appeared normal, as did the leptomeninges. There was no obstruction above or below this level, for a catheter passed freely both upwards and downwards.

Post-operatively the patient did well and 18 months after the operation was symptom free.

Case 2.-A woman, aged 18 (R.I. 198481 54), four years before admission began to have low back pain and pain at the lateral aspect of the left calf which was without preceding trauma and of gradual onset. The pain had many of the characteristics of sciatica caused by a prolapsed intervertebral disc and it was with this possibility in mind that she first came under medical care. She was admitted to hospital after conservative treatment had failed to relieve her. At the time of admission the only abnormalities on examination were very slight weakness at the left ankle which may have been partly occasioned by pain, and a little blunting of sensation to pin-prick on the outer aspect of the left lower leg. The back movements, though initially good, were later limited, as was straight leg raising on the left. Further radiographs were taken and these disclosed a dilatation of the spinal canal, as indicated by scalloping of the posterior aspect of the vertebral bodies, especially the first lumbar vertebra, and by an increase in the interpedicular distance with narrowing of the pedicles (Fig. 2). The distances between the pedicles from T.7 to T.11 were at the extreme upper limit of normal given by Elsberg and Dyke (1934), and, although the pedicles of T.12, L.1, and L.2 had a more abnormal form, they were not separated by such an unusually great distance. (The measurements were : T.7 $=22 \mathrm{~mm}$., T. $8=22 \mathrm{~mm}$., T.9 $=23 \mathrm{~mm} ., \quad$ T. $10=24 \mathrm{~mm}$., T.11 $=25 \mathrm{~mm}$., T.12 $=27$ mm., L.1 $=29$ mm., L. $2=29$ mm., L. $3=28 \mathrm{~mm} .$, L. $4=28 \mathrm{~mm} .$, L. $5=-30 \mathrm{~mm}$.) There were in addition some minor congenital abnormalities of the vertebrae. Because of the expanded vertebral canal a spinal cord tumour was suspected and a lumbar puncture showed an initial pressure of $135 \mathrm{~mm}$. of water with normal responses to jugular compression. The protein level was $40 \mathrm{mg}$. $/ 100 \mathrm{ml}$. and there were no cells. A myelogram showed no abnormality at the lumbodorsal junction and equivocal changes only at the L.4-5 disc interspace. Because the symptoms remained severe an exploration of the disc spaces at L.4-5 and L.5-S.1 on the left hand side was carried out. No abnormalities were detected. The opportunity provided by this operation was taken to explore the upper lumbar spine, and the spine and lamina of the second lumbar vertebra were removed. The bone of the lamina was unduly thick and hard. Microscopical examination of it, however, disclosed no significant abnormality. The spinal canal was seen to be enlarged, and after opening the dura it was possible to be absolutely satisfied that the cord and the spinal nerve roots were normal. Postoperatively the patient was unexpectedly relieved of her leg pain and when seen three months later was symptom free and had a full range of movements in her back.

\section{Discussion}

Enlargement of the spinal canal with congenital abnormalities of the cord is not particularly uncommon. Herren and Edwards (1940), for example, drew attention to dilatation of the spinal canal associated with duplication of the spinal cord, and the literature on diastemato-myelia contains several accounts of dilatation of the spinal canal. Earl Walker (1944) recorded abnormal enlargement of the spinal canal, apparently similar in type to that noted here, but all his patients had abnormalities of the spinal cord with resulting neurological disabilities. The two cases reported here differed from Walker's in another minor respect, for his 
patients all had abnormally short vertebral spines and the laminae were wider and thinner than normal. Although in Case 1 the spine of T.11 was short, it was not associated with a notably deformed lamina and in Case 2 the lamina appeared thicker than usual. Walker suggested that the enlargement of the spinal canal in his cases had occurred in the development of the individual. He was able to say this because the associated abnormality of the cord provided unequivocal evidence of abnormal development in that region, and the excessive size of the spinal canal clearly resulted from maldevelopment and not from pressure erosion. Among the published cases of intrathoracic meningocele enlargement of the spinal cord and erosion of some of the vertebral pedicles are, in many of the reports, either described or may be inferred to have occurred; scalloping of the posterior aspects of the vertebral bodies was a feature of some cases. These changes were well illustrated by Kessel (1951) who also referred to the previous literature. In addition Kessel quoted and illustrated a personal communication from Bull (1950) which is of considerable interest. The report concerned a 37-year-old woman with neurofibromatosis who had gross enlargement of the vertebral canal and, at necropsy (death was due to cerebral tumour), the posterior aspects of the vertebral bodies T.12-L.3 were seen to be hollowed out. The "distended theca" bulged through the large intervertebral foramina. Bull's patient may have shown a more advanced example of the abnormality described by the present writer. (See also the case reported by Mendelsohn and Kay in 1949.)

A congenital abnormality of a single vertebral pedicle sometimes occurs. In the example recorded by Steinbach, Boldrey, and Sooy (1952) one cervical pedicle appeared to be eroded, but there were no abnormal neurological findings and a surgical exploration revealed no tumour. These authors suggested that future cases might be correctly diagnosed because of the compensatory structural changes in the bone.

Case 1 reported here came under observation because of mild back pain and Case 2 had no symptoms referable to the upper lumbar spine. In neither case were there any significant neurological abnormalities, the slight changes in Case 2 being presumably referable to another pathological process. The experience of these two cases shows that when the relevant symptoms are mild, and when there are no neurological abnormalities and the lumbar puncture findings are normal, then dilatation of the spinal canal, especially when associated with congenital abnormalities of the affected vertebrae, may be regarded as a benign condition and of no serious significance. However, when pain is a prominent symptom, enlargement of the upper lumbar spinal canal associated with normal neurological findings and a normal cerebrospinal fluid may have an alternative origin. The following case which I saw at operation illustrates this. (The patient had been referred to Professor Sir Geoffrey Jefferson by Mr. D. Ll. Griffiths and I am indebted to them for permission to record these findings.)

Case 3.-A woman, aged 63, four months before operation had influenza and felt extremely and unusually ill. She shortly developed a very unpleasant upper lumbar backache which "gripped" her and from which pain, at times, spread either into the hips or down the backs of both legs to the knees. The pain continued and became unbearable, in spite of very large doses of aspirin, and admission to hospital was arranged. On examination spasm of the erector spinae muscles was severe and, although she could stand out of bed, forward flexion was impossible. Neurological examination was entirely normal. A lumbar puncture was normal with a protein level of $35 \mathrm{mg} . / 100 \mathrm{ml}$. and one white cell per c.mm.

The radiographs showed considerable erosion of the $\omega$ pedicles of T.12, L.1, and L.2 with enlargement of the or intervertebral foramina. There was no scalloping on 윽 the posterior aspects of the bodies of the affected vertebrae, but the antero-posterior measurement of the $Z$ spinal canal was greatly increased because the laminae were thinned and were lying exceptionally far posteriorly (Fig. 3). At operation the affected laminae were less deeply situated than is normal and the spinousi processes were unusually short. The bone of the laminae of L.1 and of L.2 was in parts little thicker than an egg-shell. On removing the bone a cyst cavity which extended from T.12 to L.3 (inclusive) was disclosed. Fluid from the cyst contained protein, $30 \mathrm{mg}$. $/ 100 \mathrm{ml}$., sugąr, $55 \mathrm{mg} . / 100 \mathrm{ml}$., and chlorides, $700 \mathrm{mg} . / 100 \mathrm{ml}$. The cyst cavity was roughly cigar shaped and lay dorsal to the spinal canal ; its floor was intimately fused with an altered and semi-transparent dura mater and no extradural fat was seen. The dorsal wall of the cavity was excised, and microscopical section showed it to consist of collagen with an incomplete layer of endothelial cells. No communication with the subarachnoid space could be demonstrated. The dura surrounding the spinal cord was not opened.

This lesion presumably should be classified as an extradural cyst, though it differed in several important respects from those described by Elsberg and others (1934).

\section{Summary}

Two cases are described of dilatation of the spinal canal at the thoraco-lumbar junction with an $x$-ray picture simulating an expanding lesion. In both of them full investigations, including operation, disclosed a normal cord lying in an enlarged sub- 

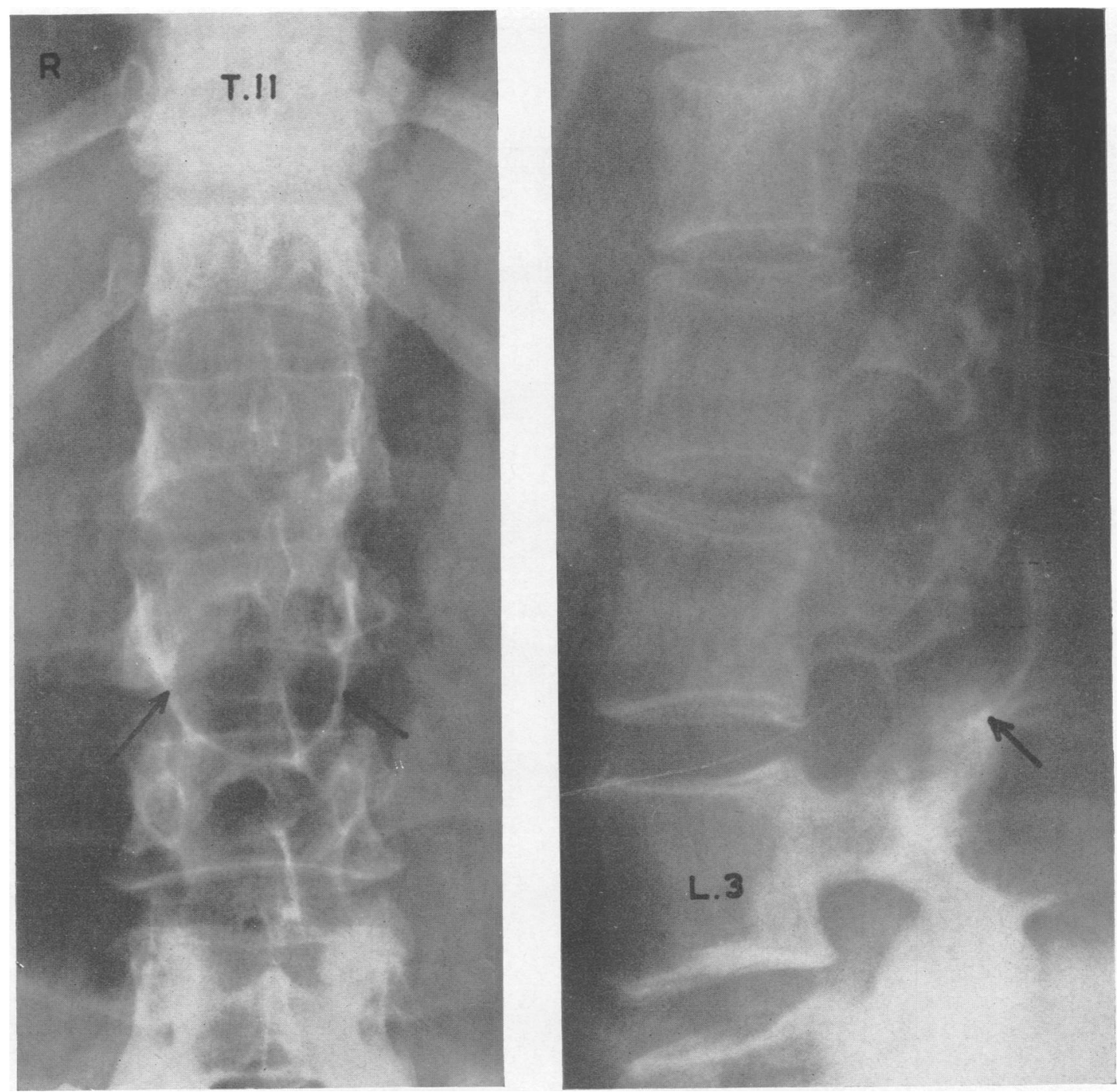

FIG. 3.-Case 3 : Radiographs of the thoraco-lumbar junction.

a. Antero-posterior view showing widening of the canal and erosion of the pedicles. Arrows indicate the well defined lower margin of extreme expansion of the lamina of L.2 (cf. lateral view).

arachnoid space. The significance of these findings is briefly discussed and the findings are contrasted with those in an unusual case of extradural cyst.

I am grateful to Mr. Joe Pennybacker for advice in the preparation of this paper and for permission to record Cases 1 and 2. Case 2 was referred by $\mathrm{Mr}$. J. C. Agerholm.

b. Lateral view, in which the canal is seen greatly widened with pedicles thinned and intervertebral canals consequently enlarged. The arrow indicates the lower margin of extreme expansion of lamina of $\mathbf{L} .2$.

\section{REFERENCES}

Bull, J. (1950). Quoted by Kessel, loc. cit.
Elsberg, C. A., and Dyke, C. G. (1934). Bull. neurol. Inst. N.Y., Elsberg, C. A., and Dyke, C. G. (1934). Bull. neuro
3, 359.

Herren, R. Y., and Edwards, J. E. (1940), Arch. Path., Chicago, $30,1203$.

Kessel, A. W. L. (1951). J. Bone Jt Surg., 33B, 87.

Mendelsohn, H. J., and Kay, E. B. (1949)., J. thorac. Surg., 18, 124. Steinbach, H. L., Boldrey, E. B., and Sooy, F. A. (1952). Radiology,

59, 838. (1944). Amer. J. Roentgenol., 52, 571.

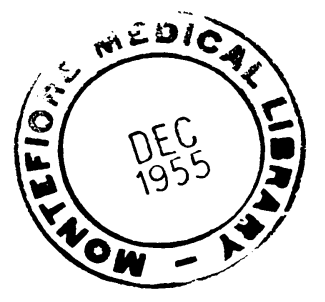

